\title{
High blood pressure in school children and adolescents in Argentina over the past 25 years: A systematic review of observational studies
}

\author{
Alejandro Díaz, M.D. ${ }^{a}$ and Luciana Calandra, M.D. ${ }^{b}$
}

\begin{abstract}
Introduction. Over the past years, hypertension has been recognized as an important health problem in the pediatric population. Asystematic review of observational studies published between 1988 and 2014 was conducted to estimate the prevalence of high blood pressure and cardiovascular risk factors among children and adolescents in Argentina.

Population and methods. Abibliographic search was done in MEDLINE, SciELO, and LILACS to look for studies on high blood pressure prevalence in school children and adolescents in Argentina. Studies and surveys that had included the measurement of blood pressure in children and adolescents (aged 5-20 years) according to the Fourth Report on the Diagnosis, Evaluation, and Treatment of High Blood Pressure in Children and Adolescents by the American Academy of Pediatrics were included in this study.

Results. Fourteen publications were identified. The pooled prevalence in 11706 subjects (random effects model) was $6.61 \%$ (95\% confidence interval [CI]: 4.30-9.37). The crudeprevalencewas 7.35\% (95\% CI: 6.88-7.83). High blood pressure was more prevalent among adolescents than children $\leq 10$ years old $(7.4 \%$ versus $4.3 \%, P=$ $0.001)$, and among boys than girls $(11.2 \%$ versus $6.8 \%, P=0.001)$. The most common risk factors included a sedentary lifestyle (50\%), overweight $(15.4 \%)$, abdominal obesity $(13.7 \%)$, obesity $(11.5 \%)$, and smoking $(6.5 \%)$.

Conclusions. Our data show that the prevalence of high blood pressure and cardiovascular risk factors in school children and adolescents is high, and this accounts for a very important public health problem in Argentina.

Key words: hypertension, child, adolescent, epidemiology, systematic review.
\end{abstract}

http:/ /dx.doi.org/10.5546/aap.2017.eng.5 of the Province of Buenos Aires, Tandil, Argentina.

E-mail address:

Alejandro Díaz, M.D.: alejandrounicen@gmail. com

Funding:

None.

Conflict of interest:

None.

Received: 5-17-2016 Accepted: 8-29-2016
$5 \%$, although it reaches $10 \%$ in some geographic regions. ${ }^{2,4-6}$

$D$ a t a from differen $t$ epidemiological studies reinforce the concept of regular blood pressure (BP) monitoring since childhood and into adulthood; in addition, and most likely, the detection of high $B P$ values during childhood may help to predict the development of sustained arterial hypertension (AHT) during adulthood. ${ }^{7}$ Although AHT is a known risk factor for morbidity and mortality in Argentina, few national, large studies have been done to assess $\mathrm{BP}$ values periodically and establish the prevalence of HBP in children and adolescents attending school in Argentina. In an attempt to fill in such knowledge gap, the primary objective of this study was to estimate the prevalence of HBP in school children and adolescents in Argentina by means of a systematic review of research studies published in the past 25 years. In addition, the secondary objective of this study was to establish the prevalence of obesity, overweight, smoking, and a sedentary lifestyle observed in the studies included in this systematic review.

\section{POPULATION AND METHODS}

This systematic review was designed and developed in accordance with the Preferred Reporting Items in Systematic Reviews and MetaAnalyses (PRISMA) Statement. ${ }^{8}$

\section{Bibliographic search strategy}

A bibliographic search was done in the following databases: MEDLINE (National Library of Medicine), SciELO (Scientific Electronic Library Online), and LILACS (Latin American and Caribbean Health Sciences 
Literature), to look for studies conducted in Argentina between January 1988 and December 2014. The following search terms were used (in English, Spanish, and Portuguese): school children, adolescents, pediatrics, hypertension, high blood pressure, prevalence, cross-sectional studies, epidemiology, and Argentina. Results were compensated with a manual search of relevant references quoted in the analyzed articles obtained from the bibliographic search.
Data from each study were extracted by a single reviewer following a standard protocol; a standard data collection form with a checklist was used. 8,9

The full-text versions of all potentially relevant articles were downloaded from the databases or requested to authors by e-mail. Two investigators selected the studies, extracted data independently, and cross-checked data; discrepancies were solved by consensus. Figure 1 summarizes the

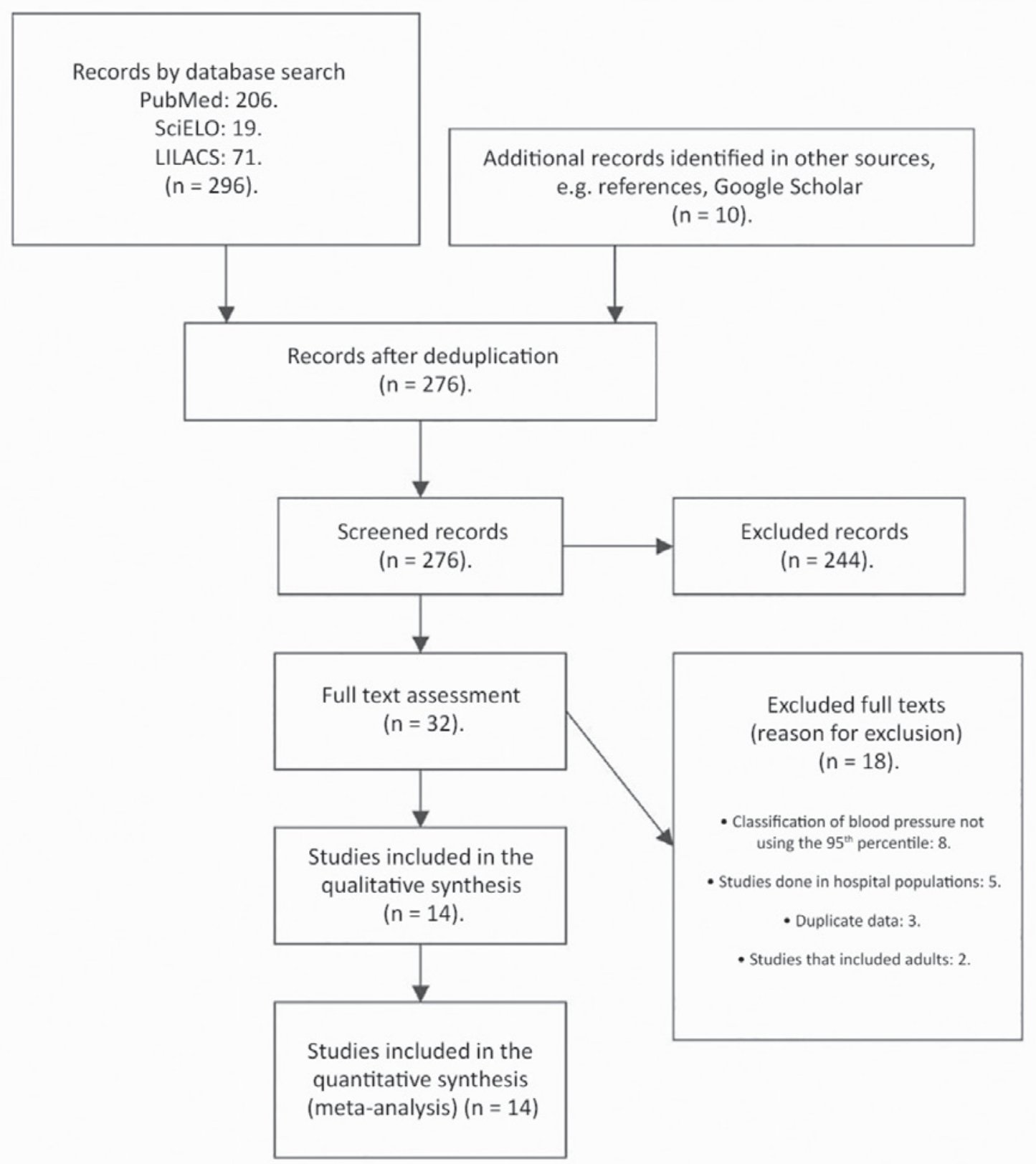


study selection process. Selected studies were assessed using an appraisal tool established for the surveillance of AHT prevalence studies in Latin America and the Caribbean. ${ }^{9}$

\section{Inclusion criteria}

Inclusion criteria were the following: 1) studies or surveys including BP measurements and HBP prevalence reports (or values that enabled $\mathrm{BP}$ estimations); 2) studies conducted in the school setting in children and adolescents (aged 5-20 years) in Argentina; 3) studies for which HBP diagnosis had been established based on the Fourth Report on the Diagnosis, Evaluation, and Treatment of High Blood Pressure in Children and Adolescents $\left(\mathrm{BP} \geq\right.$ the $95^{\text {th }}$ percentile or the use of antihypertensive drugs). ${ }^{10}$

\section{Exclusion criteria}

Studies were excluded in the following cases: 1) if participation was restricted to special populations (e.g., transplant patients, dialysis patients, series of patients with secondary HBP, or hospital database analysis); 2) if there were duplicate publications; and 3) if diagnostic criteria were different from the BP values or percentiles established in the Fourth Report on the Diagnosis, Evaluation, and Treatment of High Blood Pressure in Children and Adolescents. ${ }^{10}$

Collected outcome measures included year of study, city of study, participants' mean age, sample size, type of BP measuring device and measuring technique, definition used for HBP diagnosis.

The following was also assessed for each study: 1 ) the presence of diabetes and dyslipemia (both considered categorical, dichotomous outcome measures and defined as known diagnosis at the time of examination); 2) smoking (present smoking habit at the time of examination); 3) a sedentary lifestyle (defined as physical activity $<3$ days per week for less than 30 minutes a day); 4) abdominal obesity (considered as a categorical outcome measure and defined as a waist circumference $\geq$ the $90^{\text {th }}$ percentile, or $\geq 80 \mathrm{~cm}$ for women and $\geq 94 \mathrm{~cm}$ for men); 5) overweight (considered as a categorical outcome measure and defined as a body weight between the $85^{\text {th }}$ and the $96^{\text {th }}$ percentiles, or a Z-score $>1$ standard deviation [SD]); 6) obesity (considered as a categorical outcome measure and defined as a body weight $\geq 97^{\text {th }}$ percentile or a Z-score > 2 SD).

Data were entered in a Microsoft Office
Excel $^{\mathrm{TM}}$ spreadsheet designed in accordance with the PRISMA guidelines. ${ }^{8}$

This study was based on previously published anonymized data, so no approval from the Bioethics Committee was required.

The crude prevalence of HBP was estimated by dividing the number of subjects with HBP in each study into the total number of subjects assessed in each study. Also, the prevalence of HBP was specifically analyzed for the 5-10-year-old child group and the $>11$-year-old adolescent group. Results were described as percentage (and its corresponding 95\% confidence interval [CI]). HBP prevalence was analyzed using two models: the fixed effects model (when lack of heterogeneity is assumed among studies) and the random effects model (when the studies included in the review are assumed to account for a random sample of all existing studies). Heterogeneity among studies was quantified using the $\mathrm{i}^{2}$ statistics and tested using the Cochran's Q-test. The statistical analysis was done using the Medcalc software for Windows, version 14.8.1 (Medcalc Software, Ostend, Belgium).

\section{RESULTS}

The initial bibliographic search identified 276 studies. For the second step of the search, 244 titles and abstracts were excluded. For the third step, the full text of 32 studies was analyzed; 18 were excluded (see reason for exclusion in Figure 1). Finally, 14 studies were included in the analysis based on 11706 subjects. ${ }^{11-24}$ The analysis showed heterogeneity among studies $\left(Q=384, \mathrm{I}^{2}=96.6 \%\right.$, $P=0.0001$ ) and no publication bias. Table 1 shows the characteristics of each study, including number of participants, mean age, HBP prevalence (total and by gender), and other cardiovascular risk factors. The number of participants per study ranged between 93 and 2507 subjects.

Ten studies $(71.4 \%)$ reported the number of visits and measurements used to establish BP values. Aneroid sphygmomanometers were used in $43 \%$ of studies. Mercury sphygmomanometers and automatic electronic devices were used in $36 \%$ and $21 \%$ of studies, respectively.

Two or more BP measurements were done in a single visit in 5 studies (35.7\%). BP was measured in 2 or more visits in 5 studies $(35.7 \%)$.

\section{Prevalence of high blood pressure}

The prevalence of HBP in school children and adolescents in Argentina was 7.35\% (95\% CI: 6.887.83) (fixed effects model), and ranged between 
$1.08 \%$ and $13.4 \%$ (Figure 2). The pooled prevalence (random effects model) was 6.61\% (95\% CI: 4.309.37). Only 9 studies (64\%) reported the mean age of the study population, which was $11.6 \pm 3.6$ years. Half of studies (7) published the prevalence of HBP by gender and observed that it was higher among boys than girls $(11.2 \%$ versus $6.8 \%, P=$ 0.001 ). The prevalence of HBP increased from $4.3 \%$ in the group of children aged 5-10 years old to $7.4 \%$ in the group of adolescents $\geq 11$ years old.

None of the studies included in this analysis assessed the level of knowledge, treatment, and control of BP.

\section{Other cardiovascular risk factors}

Eleven studies reported the prevalence of obesity (average: $11.5 \%$, range: $2.2 \%-22.2 \%$ ), and only 5 studies assessed the prevalence of smoking (average: $6.5 \%$, range: $1.6 \%-10.7 \%$ ). Only 1 study reported the prevalence of dyslipemia (average: $20 \%$ ). No study reported the prevalence of diabetes.

The presence of central (abdominal) obesity was assessed only in 6 studies (prevalence: $13.7 \%$, range: $4.6 \%-21 \%$ ). The prevalence of overweight was $15.4 \%$ (range: $10.9 \%-26.3 \%$ ) and was reported in 9 studies.

The most prevalent risk factor was a sedentary lifestyle (50\%, range: $36.3 \%-61 \%$ ), and obesity was the most studied risk factor.

\section{DISCUSSION}

Data obtained in this systematic review indicate that, in Argentina, more than 1 in every 20 school children and adolescents have HBP. We also found a high prevalence of associated cardiovascular risk factors in children and adolescents. As per our knowledge, to date, this is the first systematic review of the literature done to estimate the prevalence of HBP and cardiovascular risk factors in children and adolescents in Argentina.

One of the greatest myths regarding AHT in children and adolescents is that it is an adult disease with no actual relevance in the pediatric population. ${ }^{25}$ However, recent data show that the prevalence of HBP in pediatrics is not much lower than that of other childhood diseases, such as attention deficit hyperactivity disorder or asthma ( $9 \%$ prevalence), and is much higher than some other disorders that receive dramatically more attention, such as autism or epilepsy $(1 \%$ prevalence). ${ }^{25}$

Consistent with our data, a report of the United States National Survey on Nutrition and Health (1999-2010) on 9250 children and adolescents (8-17 years old) reported a $6.07 \%$ prevalence of AHT. ${ }^{26}$ Also, recent data from a systematic review of 122053 adolescents indicate that the prevalence of HBP is higher among children and adolescents from low- and middle-income countries. ${ }^{27}$

TABLE 1. Characteristics of the 14 studies included in the systematic review of high blood pressure in 11706 school children and adolescents in Argentina, 1988-2014

\begin{tabular}{|c|c|c|c|c|c|c|c|c|c|c|c|c|c|}
\hline \multirow{2}{*}{$\begin{array}{l}\text { Main author and } \\
\text { year of the study } \\
\text { (reference) }\end{array}$} & \multirow[t]{2}{*}{$\begin{array}{l}\text { Age } \\
\text { range }\end{array}$} & \multirow[t]{2}{*}{$n$} & \multirow[t]{2}{*}{$\begin{array}{c}\text { Measuring } \\
\text { device }\end{array}$} & \multirow{2}{*}{$\begin{array}{c}\text { No. } \\
\text { of } m . \\
\mathrm{V}\end{array}$} & \multicolumn{4}{|c|}{$\begin{array}{c}\text { HBP prevalence } \\
(\%)\end{array}$} & \multirow{2}{*}{ 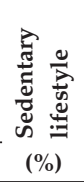 } & \multirow{2}{*}{ 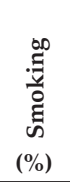 } & \multirow{2}{*}{ 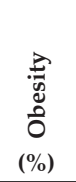 } & \multirow[t]{2}{*}{$\begin{array}{l}\vec{z} \\
.00 \\
.00 \\
\overrightarrow{0} \\
0 \\
0 \\
0 \\
(\%)\end{array}$} & \multirow{2}{*}{$\begin{array}{l}\mathrm{CO} \\
(\%)\end{array}$} \\
\hline & & & & & Total & $95 \% \mathrm{CI}$ & Male & Female & & & & & \\
\hline Morales et al., $1989^{11}$ & $7-12$ & 1018 & M & $2-3$ & 11.7 & $9.7-13.8$ & ND & ND & $\mathrm{ND}$ & ND & ND & ND & ND \\
\hline Dei-Cas et al., $2000^{12}$ & 15 & & $\mathrm{M}$ & & 7.7 & $5.1-1$ & & & 61 & 10.7 & 7.4 & ND & ND \\
\hline Martínez et al., $2001^{13}$ & $11-18$ & 2115 & $\mathrm{AN}$ & $1-1$ & 3.0 & $2.3-3.8$ & 4.7 & & ND & ND & 2.2 & 10.9 & ND \\
\hline Dumas et al., $2005^{14}$ & $6-12$ & 1038 & $\mathrm{M}$ & $2-3$ & 3.37 & $2.3-4.6$ & 3.8 & 2.8 & ND & ND & ND & ND & ND \\
\hline Poletti et al., $2007^{15}$ & $10-15$ & 2507 & $\mathrm{M}$ & $3-1$ & 13.4 & $12.0-14.7$ & 12.5 & 1.4 & 36.3 & ND & 4.5 & 17.1 & ND \\
\hline Szer et al., $2010^{16}$ & $6-10$ & 816 & $\mathrm{AN}$ & ND & 9.40 & 7.4-11.6 & 9.7 & 9.1 & ND & ND & 16.7 & 17.9 & 20.3 \\
\hline Tringler et al., $2012^{17}$ & $5-18$ & 334 & $\mathrm{M}$ & $3-2$ & 4.30 & $2.3-7.0$ & ND & ND & 50.2 & 4.4 & 9.2 & 14 & ND \\
\hline Chaila et al., $2012^{18}$ & $6-19$ & 700 & $\mathrm{AN}$ & $2-1$ & 7.0 & $5.2-9.1$ & ND & ND & ND & ND & 14 & 2 & 15 \\
\hline Gotthelf et al., $2012^{19}$ & $16-20$ & 395 & A & $2-1$ & 11.4 & $8.4-14.9$ & 19 & 5.7 & ND & 5.4 & 7.1 & 11 & 9.9 \\
\hline Abraham et al., 201 & $0-17$ & 1056 & $\mathrm{~A}$ & $3-2$ & 10.6 & $8.8-12.6$ & ND & ND & 52.5 & 1.6 & 13.3 & 18.7 & ND \\
\hline Vergottini et al., $2013^{21}$ & $15-18$ & 93 & $\mathrm{AN}$ & ND & 3.0 & & ND & ND & ND & 10.7 & 15.5 & ND & 4.6 \\
\hline Zeberio et al., $2013^{22}$ & $6-10$ & 555 & $\mathrm{~A}$ & ND & 10.8 & $0.3-2.3$ & ND & ND & ND & ND & 15.1 & 26.3 & 14.5 \\
\hline Sapag et al., $2014^{23}$ & $6-15$ & 361 & $\mathrm{AN}$ & ND & 0.13 & $0.4-3.0$ & ND & ND & ND & ND & 22.2 & 20.8 & 21 \\
\hline Hirschler et al., $2014^{24}$ & ND & 355 & $\mathrm{AN}$ & $2-1$ & 12.8 & $9.5-16.7$ & 15.9 & 9.6 & ND & 7.9 & 2.8 & ND & 10.9 \\
\hline
\end{tabular}

HBP: high blood pressure; No. of m.: number of measurements; V: visits; CO: central (abdominal) obesity; ND: no data; M: mercury; A: automatic; AN: aneroid. 
An "ideal" way to determine the prevalence of pediatric AHT in Argentina would be to conduct a national survey, with samples representative of each region, and measure $\mathrm{BP}$ in different, multiple visits to confirm the diagnosis of established AHT. In the absence of such "ideal study," systematic reviews help to collect and analyze scientific evidence, for which the analysis units are the original, primary studies. Systematic reviews and meta-analyses are essential tools to summarize available scientific information and identify areas for future research.

In spite of methodological differences among the studies included in this review, the overall prevalence of pediatric HBP in Argentina is similar to the regional prevalence reported in population studies. ${ }^{27-29}$ This systematic analysis of the prevalence of HBP in children and adolescents is an attempt to compensate the lack of national data on pediatric AHT in our country. However, results may not adequately represent indigenous or rural populations given that analyzed data were obtained from studies conducted in urban areas of Argentina. Therefore, the results of this review may not replace a prevalence study conducted at a national level.

It is worth noting that the prevalence of HBP estimated in this review may overestimate the actual prevalence of established AHT. In this regard, in the population studies included in this review, BP was generally measured in a single visit, which provided an incidental estimation of prevalence, and should, therefore, be clearly differentiated from sustained AHT.

Also, it is known that, based on the regression toward the mean and repeated measurements, the initial HBP prevalence may decrease to less than $5 \%{ }^{2,4}$ A study conducted in adolescents with an initial HBP prevalence of $9.4 \%$ reported a reduction to $3.2 \%$ after the third control. ${ }^{29} \mathrm{In}$

FIGURE 2. Forest plot for the estimated prevalence of high blood pressure (squares) and 95\% confidence intervals (bars) of the 14 studies (n: 11 706) included in the systematic review of high blood pressure in school children and adolescents in Argentina, 1988-2014a

Morales, 1989

Dei-Cas, 2000

Ḿartinez, 2001

Dumas, 2005

Poletti, 2007

Szer, 2010

Tringler, 2012

Chaila, 2012

Gotthelf, 2012

Abraham, 2013

Vergottini, 2013

Zeberio, 2013

Sapag, 2014

Hirschler, 2014

Total (fixed effects)

Total (random effects)

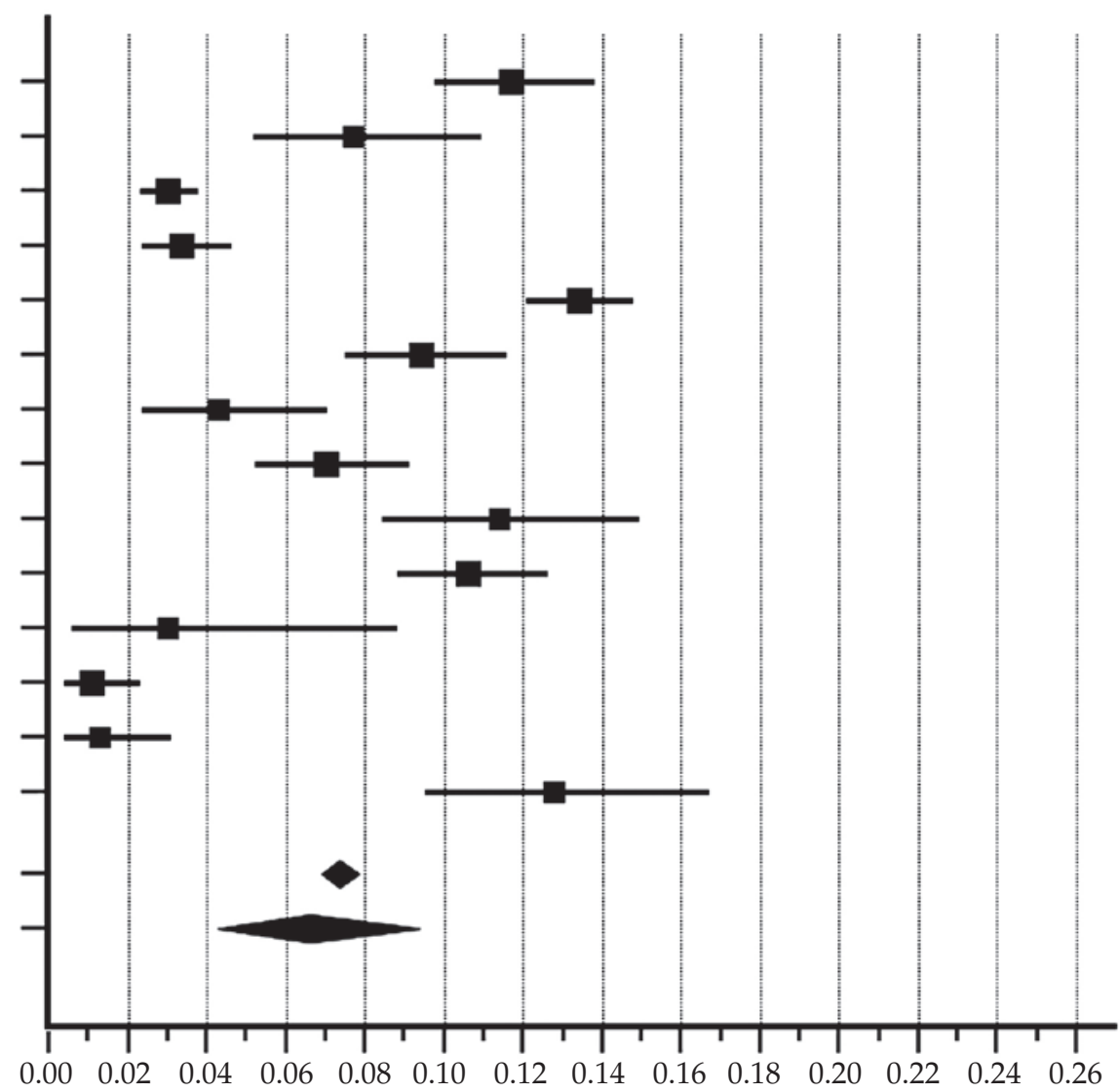

a The pooled ratio of estimated children and adolescents with high blood pressure is represented by the diamond. 
addition, the Belo Horizonte Study reported that the initial prevalence of $6.5 \%$ declined to $3.5 \%$ after the second measurement. ${ }^{30}$

Although the definition of overweight, obesity, and abdominal obesity was not homogeneous across studies, it is worth noting that our data show a higher prevalence of obesity than that reported in the National Survey on School Health. ${ }^{31}$

The pooled prevalence of childhood overweight and obesity has increased at a fast pace in most Latin American and Caribbean countries, and ranges between $18.9 \%$ and $36.9 \%$ in school children and between $16.6 \%$ and $35.8 \%$ in adolescents. ${ }^{32}$

In pediatrics, $\mathrm{HBP}$ is determined by multiple factors; therefore, it is important to warn patients and their parents on lifestyle, eating habits, body weight and physical activity changes. ${ }^{33} \mathrm{~A}$ sedentary lifestyle during childhood increases the risk for HBP in a two-year follow-up. ${ }^{34}$

In our study, a low level of physical activity was the most common risk factor, and its prevalence was similar to that reported in the Argentinean National Survey on School Health. ${ }^{31}$ It was comparable to the rate of sedentary lifestyle reported in children and adolescents in Brazil ${ }^{34}$ and other Latin American countries. ${ }^{35}$

Prevention and treatment of cardiovascular risk factors are an ongoing challenge for pediatricians. In this regard, the Argentine Society of Pediatrics has established guidelines to implement effective prevention strategies, an early detection and treatment of cardiovascular risk factors in pediatrics. $^{36}$

\section{Limitations}

This systematic review poses certain limitations. First of all, there are variations among the different studies in terms of age structure and BP measurement techniques. This restricts the possibility of making reliable comparisons among studies and hinders the adjustment of prevalence rates by age group. Also, the prevalence of risk factors associated with the development of HBP (a sedentary lifestyle, diabetes, obesity, etc.) is not comparable given the differences in methodology and the varying diagnostic criteria used. Lastly, the heterogeneous prevalence of HBP within each study was high; this may be attributed to differences in genetic, regional, and environmental factors, as well as different lifestyles (smoking, physical activity, and salt intake).

\section{CONCLUSIONS}

In spite of the relatively limited evidence, we observed a high prevalence of HBP and cardiovascular risk factors in school children and adolescents in Argentina, and this accounts for an important public health problem in Argentina.

\section{REFERENCES}

1. Lurbe E, Cifkova R, Cruickshank JK, Dillon MJ, et al. Management of high blood pressure in children and adolescents: recommendations of the European Society of Hypertension. J Hypertens 2009;27(9):1719-42.

2. Sorof JM, Lai D, Turner J, Poffenbarger T, et al. Overweight, ethnicity, and the prevalence of hypertension in schoolaged children. Pediatrics 2004;113(3 pt 1):475-82.

3. Falkner B. Hypertension in children and adolescents: epidemiology and natural history. Pediatr Nephrol 2010;25(7):1219-24.

4. Marras AR, Bassareo PP, Ruscazio M. The prevalence of paediatric hypertension, emphasising the need to use specific population references: the Sardinian Hypertensive Adolescents Research Programme Study. Cardiol Young 2009;19(3):233-8.

5. Bassareo PP, Marras AR, Mercuro G. About the need to use specific population references in estimating paediatric hypertension: Sardinian BP standards (age 11-14 years). Ital J Pediatr 2012;38:1.

6. Bassareo PP,Mercuro G. Pediatrichypertension: An update on a burning problem. World J Cardiol 2014;6(5):253-9.

7. Chen X,Wang Y. Tracking of blood pressure from childhood to adulthood: a systematic review and meta-regression analysis. Circulation 2008;117(25):3171-80.

8. Moher D, Liberati A, Tetzlaff J, Altman DG. Preferred reporting items for systematic reviews and meta-analyses: the PRISMA statement. PLoS Med 2009;6(7):e1000097.

9. Burroughs Peña MS, Mendes Abdala CV,Silva LC, Ordúñez P. Usefulness for surveillance of hypertension prevalence studies in Latin America and the Caribbean: the past 10 years. Rev Panam Salud Pública 2012;32(1):15-21.

10. National High Blood Pressure Education Program Working Group on High Blood Pressure in Children and Adolescents. The fourth report on the diagnosis, evaluation, and treatment of high BP in children and adolescents. Pediatrics 2004;114(2 Suppl, 4th Report):555-76.

11. Morales MS, Ricart AO, Cid OA. Presión arterial infantil: Estudio epidemiológico en 1018 niños, análisis de algunos factores de riesgo. Hipertensión arterial y nivel socioeconómico. Rev Arg Cardiol 1989;57(6):374-80.

12. Dei-Cas SA, Dei-Cas IJ, Dei-Cas PG, Szyrma ME, et al. Estudio de la presión arterial en adolescentes de 15 años. Su relación con características antropométricas y factores de riesgo de hipertensión arterial. Arch Argent Pediatr 2000;98(3):161-70.

13. Martínez CA, Ibáñez JO, Paterno CA, De Roig Bustamante MS, et al. Sobrepeso y obesidad en niños y adolescentes de la ciudad de Corrientes. Asociación con factores de riesgo cardiovascular. Medicina (B Aires) 2001;61(3):308-14.

14. Dumas LV, López Cross SA, Peroni DS, Valenzuela GM. Detección de hipertensión arterial en niños en edad escolar. Rev Fac Cienc Méd (Córdoba) 2005;62(3):47-52.

15. Poletti OH, Barrios L. Obesidad e hipertensión arterial en escolares de la ciudad de Corrientes, Argentina. Arch Argent Pediatr 2007;105(4):293-8.

16. Szer G, Kovalskys I, De Gregorio MJ. Prevalencia de sobrepeso, obesidad y su relación en hipertensión arterial y centralización del tejido adiposo en escolares. Arch Argent 
Pediatr 2010;108(6):492-8.

17. Tringler M, Rodriguez EM, Aguera D, Molina JD, et al. High blood pressure, overweight and obesity among rural scholars from the Vela Project: a population-based study from South America. High Blood Press Cardiovasc Prev 2012;19(1):41-6.

18. Chaila Mz, Fabio S, Quiroga E, Sánchez de Boeck N, et al. Prevalencia deSíndromemetabólicoenniñosy adolescentes según diferentes criterios diagnósticos y su correlación con niveles deleptina y adipolectina. Rev Argent Endocrinol Metab 2012;40(3):103-14.

19. GotthelfSJ, Fonseca MJ. Hipertensión arterial y suasociación con variables antropométricas en adolescentes escolarizados de la ciudad de Salta (Argentina). Rev Fed Arg Cardiol 2012;41(2):96-102.

20. Abraham W, Blanco G, Coloma G, Cristaldi A, et al. ERICA Estudio de los factores de Riesgo Cardiovascular en Adolescentes. Rev Fed Arg Cardiol 2013;42(1):29-34.

21. Vergottini JC, Olmedo MB, Jorge A, González M, et al. Detección de factores de riesgo para enfermedades renal en adolescentes. Revista de Salud Pública 2013;17(2):63-72.

22. Zeberio N, Malpeli A, Apezteguía M, Carballo MA, et al. El estado nutricional de niños escolares y su relación con la tensión arterial. Arch Argent Pediatr 2013;111(2):92-7.

23. Sapag M, Dioverti C, Paramio L, Petronace A, et al. Evaluación nutricional y de tensión arterial en niños de dos escuelas de población vulnerable de Cutral Co y Plaza Huincul. Estudio cuantitativo y cualitativo. Arch Argent Pediatr 2014;112(4):337-44.

24. Hirschler V, Maccallini G, Molinari C, Urrutia I, et al. Association between Non-Traditional Risk Factors and Metabolic Syndrome in Indigenous Argentinian School Children. Diabetes Technol Ther 2014;16(2):84-90.

25. Samuels J. The increasing burden of pediatric hypertension. Hypertension 2012;60(2):276-7.

26. Chen L, Simonsen N, Liu L. Racial Differences of Pediatric Hypertension in Relation to Birth Weight and Body Size in the United States. PLoS One 2015;10(7):e0132606.
27. De Moraes AC, Lacerda MB, Moreno LA, Horta BL, et al. Prevalence of high blood pressure in 122,053 adolescents: a systematic review and meta-regression. Medicine (Baltimore) 2014;93(27):e232.

28. Magliano ES, Guedes LG, Coutinho ES, Bloch KV. Prevalence of arterial hypertension among Brazilian adolescents: systematic review and meta-analysis. $B M C$ Public Health 2013;13:833.

29. McNiece KL, Poffenbarger TS, Turner JL, Franco KD, et al. Prevalence of hypertension and pre-hypertension among adolescents. J Pediatr 2007;150(6):640-4, 644e1.

30. Oliveira RG, Lamounier JA, Oliveira AD, Castro MD, et al. Blood pressure in school children and adolescents - The Belo Horizonte study. J Pediatr (Rio J) 1999;75(4):256-66.

31. Ferrante D, Linetzky B, Ponce M, Goldberg L, et al Prevalencia de sobrepeso, obesidad, actividad física y tabaquismo en adolescentes argentinos: Encuestas Mundiales de Salud Escolar y de Tabaco en Jóvenes, 20072012. Arch Argent Pediatr 2014;112(6):496-503.

32. Rivera JÁ, De Cossío TG, Pedraza LS, Aburto TC, et al. Childhood and adolescent overweight and obesity in Latin America: a systematic review. Lancet Diabetes Endocrinol 2014;2(4):321-32.

33. Lima EM. Assessment of risk factors associated with elevated blood pressure in children and adolescents. J Pediatr (Rio J) 2004;80(1):3-4.

34. De Moraes AC, Carvalho HB, Siani A, Barba G, et al. Incidence of high blood pressure in children - effects of physical activity and sedentary behaviors: the IDEFICS study: High blood pressure, lifestyle and children. Int J Cardiol 2015;180:165-70.

35. De Moraes AC, Guerra PH, Menezes PR. The worldwide prevalence of insufficient physical activity in adolescents; a systematic review. Nutr Hosp 2013;28(3):575-84.

36. Grupo de hipertensión. Consenso sobre factores de riesgo de enfermedad cardiovascular en pediatría: Hipertensión arterial en el niño y el adolescente. Arch Argent. Pediatr 2005;103(4):348-57. 